\title{
A teologia do puro e do impuro como representação de controle social
}

\author{
Theology of the pure and the impure as a representation of social control \\ Mariana Eugenio Schietti* e Luiz Alexandre Solano Rossi * *
}

* Mestre em Teologia pela
Pontifícia Universidade Cató-
lica do Paraná. Doutoranda
em Teologia pela Pontifícia
Universidade Católica do Pa-
raná. Tutora na Faculdade
Teológica Sul Americana,
Londrina, Brasil.
mariana.schietti@gmail.com
* * Doutor em Ciências da
Religião pela Universidade
Metodista de São Paulo e
Mestre em Teologia pelo Ins-
tituto Superior Evangélico de
Estudios Teológicos, Argen-
tina. Professor do Programa
de Pós-Graduação em Teolo-
gia da Pontifícia Universidade
Católica, Curitiba, Brasil, e
no Centro Universitário inter-
nacional, Curitiba, Brasil.
luizalexandrerossi@yahoo.com.br

Recebido em: 04/12/2021

Aprovado em: 20/07/2021

Licença Creative Commons CC BY-NC 4.0 (c) (i) (9)

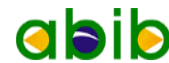

Associação Brasileira de Pesquisa Bíblica

\section{Resumo}

O período denominado de pós-exílio produzirá uma compreensão diferente a respeito do que deveria ser considerado puro e impuro. Aqueles que retornaram do exílio da Babilônia, com o objetivo de intensificar o exercício do poder político e econômico, reorganizaram os conceitos de puro e impuro como uma representação de controle social. Nesse sentido, o discurso religioso se torna uma forma de poder, capaz de reorganizar o espaço social de modo que os puros possam ser equipados aos que estão no centro e os impuros aos que estão na periferia, termos utilizados para explicar a dinâmica social que se cria ao redor dos conceitos de santidade $\mathrm{e}$ impureza.

Palavras-chave: Puro. Impuro. Controle Social. Pós-Exílio. Judaísmo.

\begin{abstract}
The post-exile period produced a different understanding of what should be considered pure and impure. Those who returned from the Babylonian exile, aiming to intensify the exercise of political and economic power, reorganized the concepts of pure and impure as a representation of social control. In this sense, the religious discourse becomes a form of power, capable of reorganizing the social space in such a way that the pure can be equated with those in the center and the impure with those on the periphery, terms used to explain the social dynamic that is created around the concepts of holiness and impurity.
\end{abstract}

Keywords: Pure. Impure. Social control. Post-exile. Judaism.

\section{Introdução}

Inicialmente é importante destacar que para que um sistema funcione sob o crivo do puro e do impuro, no qual o impuro é errado, ilícito e deve ser rejeitado, exige-se por parte de alguns, além do poder de simplesmente controlar, o poder de punir por causa de uma presumida impureza. Foucault $(1999$, p. 98), advertindo sobre questões universais acerca 
do poder da punição, afirma que quando crescem as especificações de práticas ilegais, juntamente com isso é preciso haver "uma extensão e um afinamento das práticas punitivas". E sobre esse exercício de poder acrescenta:

\begin{abstract}
O exame combina as técnicas da hierarquia que vigia e as da sanção que normaliza. É um controle normalizante, uma vigilância que permite qualificar, classificar e punir. Estabelece sobre os indivíduos uma visibilidade através da qual eles são diferenciados e sancionados. É por isso que, em todos os dispositivos de disciplina, o exame é altamente ritualizado. Nele vêm-se reunir a cerimônia do poder e a forma da experiência, a demonstração da força e o estabelecimento da verdade. No coração dos processos de disciplina, ele manifesta a sujeição dos que são percebidos como objetos e a objetivação dos que se sujeitam. A superposição das relações de poder e das de saber assume no exame todo o seu brilho visível (FOUCAULT, 1999, p. 209).
\end{abstract}

Compreende-se, a partir de Foucault, que é justamente a união entre o poder e o saber que torna o controle mais intenso e efetivo. O processo de regulamentação do comportamento por meio da aplicação de uma ou várias sanções revela, de um lado, a sujeição de indivíduos e, de outro lado, o empoderamento de alguns. Os que aceitam passivamente a dominação, alienando-se da realidade e aceitando uma hierarquia vigiante que define $o$ que é correto ou incorreto, tornam-se objetos do que Foucault chama de exame ritualizado. O ritual de examinar e tornar diferente os que não seguem os comportamentos impostos, para sancioná-los, é na verdade uma manifestação pública do poder e da experiência de exercê-lo, demonstrando força e domínio e estabelecendo a todos, por coação, a verdade que deve imperar.

Neste sentido, a teologia que deveria propor uma reflexão disciplinada sobre a realidade de Deus e seu envolvimento com o mundo, a fim de esclarecer seus propósitos e seu agir (KIRK, 2006, p. 25), tornou-se apenas um meio de legitimar o discurso de líderes sedentos por poder. E isso se deu através da classificação do puro e do impuro, como sendo o lícito e o ilícito diante de Deus. Diferenciações entre sagrado e profano, santo e pecador, puro e impuro, foram as tipologias que viabilizaram o estabelecimento da hierarquia punitiva e controladora.

A fim de compreender como a teologia do puro e do puro foi capaz de exercer o controle social no povo de Israel, faz-se necessário resgatar aspectos do Israel pré-exílico que elucidam as transformações ocorridas no pós-exílio. Sendo este último período o responsável pela construção de uma fé que se volta ao Templo e à Lei, e que passa a definir quem são os aceitos por Deus e quem são os rejeitados. Não só isso, propõem em nome de Deus, um comportamento separatista e exclusivista, em que os santos devem estar separados dos não santos e os eleitos de Deus devem assumir sua superioridade diante dos não eleitos.

\title{
2 Variações de sentido de um mesmo termo
}

No período pré-exílico a santificação estava ligada à ideia de delimitação dos espaços e momentos específicos, mantendo o sagrado distante da vida comum e pura do povo de Israel. Melhor explicando, a santificação era uma exigência específica de determinados cenários comunitários, como a travessia do Jordão por exemplo, mencionada em Josué 6 , na qual, conforme versículo 5, o povo precisa se santificar para ver as maravilhas que Javé 
faria no próximo dia. Podemos falar também da guerra santa, dos cultos, da arca da aliança e daqueles indivíduos escolhidos para função de guarda dela, dentre outros. O que era santo era intocável, era exceção, era perigoso. Conforme Douglas: "O sagrado precisa estar continuamente cercado com proibições. O sagrado deve ser sempre tratado como contagioso porque relações com ele restringem-se a ser expressas por rituais de separação e de demarcação" (DOUGLAS, 1966, p. 35).

O texto de Ezequiel 44,23 permite compreender melhor a ideia da pureza e da impureza no pré-exílio quando comparado à tradução da LXX e as profundas mudanças ocorridas, nas quais inverteu-se a compreensão do sagrado. O texto da versão Nova Bíblia Pastoral (2014), apresentado abaixo, assemelha-se às demais versões de grande circulação em português, como Almeida Corrigida e Atualizada, Nova Versão Internacional e Bíblia de Jerusalém.

"Deverão ensinar meu povo a distinguir entre sagrado e profano, e farão que ele conheça a diferença entre puro e impuro" (Ez 44,23, grifo nosso).

Nota-se que as ordens das palavras "puro" e "impuro" foram invertidas quando comparadas ao Texto Massorético e à LXX. Propomos uma tradução literal de Ez 44,23, feita a partir da Bíblia Hebraica Stuttgartensia (1990, p. 981), conservando a ordem original do texto hebraico:

Deverão ensinar meu povo a distinguir entre sagrado e profano lhe farão conhecer a diferença entre impuro e puro.

Aparentemente a inversão dos termos não é importante, entretanto, quando se observa de forma cuidadosa, fazendo aplicação do paralelismo, isso tem muita relevância.

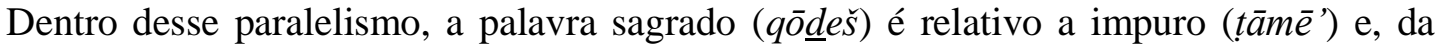
mesma forma, a palavra profano $(h \bar{o} l)$ é alusivo a puro (tâhhôr), ou seja, ao falar sobre o conhecimento do sagrado, fala-se do conhecimento do que é impuro como associação. "O sagrado contamina. Só pode ser tocado por mãos preparadas. O sagrado é 'tabu', intangível" (GALLAZZI, 2002, 172, grifo do autor). Para Zabatiero (2019, p. 131) trata-se de uma nova compreensão do nexo secular-religioso, não compreendido como opostos, mas um como sendo o outro lado do outro, o que ele chama de "a unidade do duplo". Nesta nova compreensão, explica Zabatiero, também está a compreensão moderna sobre o sagrado e o profano, que também são "a duplicação de um no outro, a dobra que evidencia a igualdade desigual de sagrado e profano". Sobre este intercâmbio de sentido com as palavras, o autor afirma que:

[...] na figura do homo sacer (delineada de novo por Agamben) romano ou na figura do sagrado na tradição bíblica hebraica, em que sagrado é o que contamina o que torna as mãos impuras, o sagrado que não só se concretiza no sacrifício que elimina a impureza, mas no sacrifício que gera a impureza, de fato, que é a própria impureza, de modo que precisa ser expiado (ZABATIERO, 2019, p. 132).

Assentindo com essa teoria, Douglas (1966, p. 20) afirma que há um consenso sobre os antepassados não fazerem distinção clara entre santidade e sujeira. Esta mesma autora, fazendo uso dos estudos de Eliade, indica que "a ambivalência do sagrado não está apenas na ordem psicológica (por atrair ou repelir), mas também na ordem dos valores; o sagrado 
é ao mesmo tempo 'sagrado' e 'maculado"' (DOUGLAS, 1966, p. 20). Essa ambivalência nos termos é o que se chama de "tabu".

Seguindo com esta defesa, Gallazzi (2002, p. 20) afirma que há uma mistura entre o "tabu da santidade" e o "tabu da poluição", uma vez que na mente do selvagem a ideia de poluição e de santidade "não estão ainda diferenciadas". Borg (1984, p. 9), da mesma forma, ao trazer algumas definições sobre a pureza, afirma que é possível considerar puro "todo o lugar" ou "tudo em seu lugar", de forma que o que está "fora do lugar" é impuro. Portanto, neste sentido, pode-se dizer que aquilo que está retirado do lugar, separado do lugar, inacessível, é impuro. Ou seja, por este pensamento, tudo o que está para além do comum, do ordinário, é impuro. Enquanto tudo o que é ordinário é puro.

Já na teologia que se construiu após o exílio encontra-se uma subversão à ordem que vigorou até o exílio. A ideia do alcance do sagrado no pós-exílio torna-se base para organização social do estado do segundo templo, fazendo crer que todos deveriam, por ação humana, atingir e manter um estado de santidade. O sagrado, deste modo, torna-se o comum, o puro, alcançável, desejado, enquanto o profano torna-se incomum, impuro e punível. Pode-se, portanto, afirmar que toda a teologia do puro e do impuro no pré-exílio se inverteu no pós-exílio.

Além disso, a busca pela purificação através do sagrado não tinha sentido algum no período pré-exílico, pois acessar o sagrado sem que houvesse o devido preparo para isso, tornaria o indivíduo impuro ou até mesmo lhe causaria morte. A purificação, deste modo apresentada, ocorria fora do espaço sagrado, longe do intocável, do impuro, longe da habitação do transcendente. O sagrado aqui é algo incomum, é algo separado de tudo, que não deve ser almejado, do qual ninguém deve se aproximar, a menos que haja um motivo. O comum da vida, o cotidiano do povo, ou seja, o profano, esse sim era puro, esse mantinha a vida, ou seja, estar vivo indicava justamente manter o devido distanciamento do sagrado.

Seguindo com essa percepção do sagrado pré-exílica, e tentando uma conceituação mais objetiva do termo para compreendê-lo como puro ou impuro, é necessário voltar à raiz hebraica de $q-\underline{d}-\check{s}$, usualmente traduzida como santo, e santo baseado na ideia de separação. Ronald Knox (apud DOUGLAS, 1966, p. 20), sabendo da dificuldade de traduzir literalmente $q-\underline{d}-\underline{s}$ para santo, utiliza em sua versão do Antigo Testamento a expressão "posto à parte". Da mesma forma, James Strong (2002, p. 910), em seu dicionário bíblico, ao tratar sobre o substantivo qō $\underline{d} e \check{s}$, traduzido como "separado, santidade, sacralidade, posto à parte", afirma que sua raiz primitiva está na palavra qā $\underline{d} a \check{s}$, que significa "ser colocado à parte, ser consagrado. Consagrado, proibido, manter alguém à parte ou separado" (STRONG, 2002, p. 909).

Neste mesmo entendimento estão Westermann e Jenni (1997), os quais apresentam a palavra $q \bar{o} \underline{d} e \check{s}$ como um status inerente à divindade, que pode ser traduzido como puro ou consagrado. Eles também afirmam que o frequente uso do termo "separado" como opção de tradução é válido quando se tratar da separação do profano, seja para proteger a divindade, seja para proteger-se da divindade. O status de puro, segundo os autores, é algo intrínseco na divindade, é independente de qualquer outra coisa ou pessoa. Afirmam, também, que as questões éticas são secundárias quando se fala de qō̄deš e outras variações vindas desta raiz.

Compreender a divindade como aquela que está posta à parte, é compreender e reconhecer sua intocabilidade. Mas em que sentido sua intangibilidade se diferencia da impureza nos moldes estabelecidos posteriormente no pós-exílio? Uma possível resposta para essa pergunta está na teoria apresentada por Douglas (1966), na qual a problemática 
do relacionamento com o sagrado, que acaba por torná-lo contagioso, é o fato de que os deuses são ideias projetadas e criadas pela experiência da sociedade e não há para eles uma referência concreta. Por isso, são ideias sem raízes, fluidas, capazes de serem desfocadas caso seja "tocada" por diversas pessoas. O imaginário se mantém seguro e estático se colocado à parte.

A alteração desse conceito acontece quando o povo escolhido por Javé passa a ser santo também. São santos porque são separados para Javé, e a santidade de Javé ganha destaque por si só. A santidade divina não é mais um complemento, passa a ser um fim em si mesma. Portanto, a força que atuava de forma automática naquilo que era santo e consagrado, já não atua mais. A realidade dos espaços santos poderia até ser profanada pelo povo de Javé, mas o espaço em si já não poderia mais ter status profano, causando morte no povo que ali adentrasse ou o tocasse.

Percebe-se claramente que "a relação com a santidade deixa de ser uma relação mágica e passa a ser uma relação 'ética' que comporta a adesão ou a negação por parte da pessoa" (GALLAZZI, 2002, p. 174), o que Borg (1984, p. 9) argumenta ser um "sistema de pureza" ou uma "sociedade de pureza" em que santidade e pureza se tornam uma dinâmica cultural que define os judeus.

A inversão na compreensão dos termos se dá quando o impuro antes portador do sagrado e, por isso, "intocável", passa, pouco a pouco, a ser considerado como feio, imperfeito, doente, o que tem menos vida. O que antes é "comum" e tido como puro, tornase agora impuro justamente por ser "comum". Um exemplo de mudança que se percebe com relação à vida, é o tratamento dado aos cadáveres que se tornaram impuros justamente por não possuírem mais a vida ou no original, o nepeš.

Nepeš, como explica Wolff (2007, p. 34) é a expressão utilizada em Gn 2,7 para expressar o conjunto total do ser humano, seu corpo e sua respiração, o que torna o ser um vivente. O termo está relacionado a órgãos como guela, boca, garganta, e outros que fazem as funções vitais como alimentação e respiração. Sem nepeš, não há vida.

Pois bem, anteriormente, tocar o sagrado ou adentrar em sua presença resultava em morte, em perda do nepeš, o ser vivente, não mais vive ao entrar em contato com o sagrado. A presença do sagrado até aqui estava, de certa forma, em oposição à vida. Consequentemente, o nepeš permanecia intocado quando se mantinha no comum, distante da delimitação do sagrado, o comum garantia continuar respirando, comendo, bebendo, era o ânimo do corpo sendo protegido aqui. Somente quando há uma preparação específica para estar no sagrado é que o nepeš, então, estava protegido.

De forma oposta, aparentemente, na teologia pós-exílica afirma-se que é no contato com o sagrado que se encontrava a vida, que se mantinha o nepeš, já o contato fora dos espaços sagrados e do que é por ele controlado, passou a ser maculado, impuro, profano, em seu sentido sujo e prejudicial. O sagrado, que antes tirava a vida, passou a mantê-la. Assim também acontecia nas outras áreas da vida cotidiana.

A partir dessas transformações, que passavam a considerar como impuro o que era imperfeito, defeituoso e comum, as realidades que envolviam as ações cotidianas, as famílias, as pessoas, de alguma maneira, eram atingidas por uma atmosfera geral de impureza, de contaminação, de profanação. Por isso, somente aqueles que deixavam a vida comum, como é o caso dos sacerdotes, eram capazes de alcançar a santidade nesse novo sentido. Já o povo, vivia sob a acusação constante e a culpa da impureza, merecedora de sanção. 


\section{Pureza e impureza como exercício de poder no pós-exílio}

O exílio foi o fator determinante para o início da mudança de consciência dos que viviam no exílio, elaborando uma nova teologia que descrevia a relação entre o povo e seu Deus, o que trazia implicações na forma como se organizavam socialmente. As questões ligadas à santidade se tornaram o cerne da vida dos judaístas após o exílio.

Sobre essa nova teocracia sadocita, Borg (1984, p. 14), Kessler (2009, p. 163), Scardelai (2012) e Gallazzi (2002, p. 178) concordam que foi o exílio que despertou a consciência dos líderes exilados para a necessidade de uma mudança radial em sua teologia. Nesse processo, os exilados (golá) constataram que a santidade de Deus, como entendida anteriormente, não garantiu uma imunidade diante da dominação Babilônica. Da mesma forma, a santidade estática do Templo e da herança davidica não evitaram a tragédia.

Desenvolveu-se, também, a ideia do profano na condição oposta à condição de santo. A divisão entre o santo e profano aparece pouco nos textos pré-exílicos, porém ganha um espaço grande nos textos exílicos e pós-exílicos, indicando, de uma maneira geral, que profano era tudo o que estava em contraposição a santo, separando um espaço santo de um espaço profano. No espaço profano, por sua vez, tudo estava contaminado, tudo era impuro e capaz de tornar impuro aquele que nele estava inserido. Neste momento o profano e o impuro ganhavam importâncias diferentes de acordo com a realidade em que estavam inseridas. Para cada grau de profanação e de impureza havia uma sequência de ritos a serem seguidos para alcance da purificação, isto é, uma espécie de sanção ressocializadora. "As diferentes situações de santidade serão os elementos constitutivos e legitimadores da estratificação social e de suas relações internas" do povo judeu, segundo Galazzi (2002, p. 185), que também comenta como se dava essa relação anteriormente:

\footnotetext{
Estas categorias não representam nenhum elemento 'central' no esquema cultural pré-exílico. Sua presença é marginal, delimitada e sobretudo, ocasional. A não ser no caso da idolatria, sobretudo na boca dos profetas e que pode muito bem ser um uso metafórico, as situações de pureza e de impureza não dependem diretamente da vontade humana. Trata-se de 'situações de fato' que não têm nada a ver com os 'mandamentos'. O mandamento, quando há, tem a função protetora: para evitar a situação de profanação e de impureza (GALLAZZI, 2002, p. 186).
}

Marianno (2011, p. 126) defende a existência de dois modelos de santidade ao longo da história do povo de Israel, a "santidade estática e santidade dinâmica". A primeira se tratava apenas da condição de eleito de Israel, a segunda estava atrelada a uma constante purificação que os sacerdotes estabeleceram. Essa santidade dinâmica tinha relação com um constante cumprimento da lei, nela era possível a purificação, a expiação e o status de puro. Com isso, a impureza também se tornava dinâmica. As transgressões morais, os fluídos físicos, eram sempre capazes de pôr em risco a santidade dinâmica. O impacto social que essa ideologia trazia ao sistema de comunidade vivido pelos deportados era determinante. A prática de exclusão, a divisão entre ações puras e impuras, os ritos, assim como a fidelidade cega à lei, se iniciaram nesse momento. As "concepções sobre pureza ritual ficaram cada vez mais refinadas na mente deste grupo" (MARIANNO, 2011, p. 127) e "desenvolveu-se, a partir daí uma concepção de pureza ligada à pureza corporal que se funde num paradigma teológico baseado no dito do Levítico que diz: 'sede santo porque eu sou santo"” (MARIANNO, 2011, p. 127). 
É sobre os novos moldes da purificação que se encontra "a maior novidade do esquema sacral montado pelos sacerdotes" (GALLAZZI, 2002, p. 190), pois o que antes era inalterável, até mesmo pelo próprio Deus, pode, então, ter a capacidade de se tornar puro por meio de ritos, gestos e tempos de espera. Como se pode observar, a porta para o comércio da purificação se abriu e, juntamente com ela, a porta para o exercício do poder de vigilância, de punição, de desclassificação de uns e enaltecimento de outros. Inúmeros ritos foram criados: tipos de sacrifícios, forma de afastamento, dias específicos para cada tipo de purificação e, obviamente, a necessidade do sacerdote como interventor. Não só havia um desempenho de energia emocional para cumprir as ordenanças da lei, como também era necessário um desempenho financeiro, seja no sacrifício do animal, no deixar de trabalhar para afastar-se e cumprir o tempo de purificação, dentre outras.

O pós-exílio trouxe um exacerbado enfoque no cumprimento do sábado, que era o principal traço identitário de Israel, além de uma rigorosa proibição ao matrimônio com mulheres estrangeiras e da insistência no pagamento fiel dos dízimos e primícias. "Por fim, urgiu-se o cumprimento do "código de santidade", disposto pela lei, como uma estratégia de separação do impuro, do não santo, do afastado de Deus" (PAGOLA, 2014, p. 237).

Analisando as regras de impureza e pureza que foram criadas a partir da ótica de sobrevivência, Smith (apud DOUGLAS, 1966, p. 26) as considerou como irracionais e impossíveis de serem cumpridas. Por um lado, percebe-se uma necessidade dos deportados em se protegerem do que era desconhecido, do que era perigoso, do que era novo. Essa proteção se deu através de um resgate da lei mosaica, interpretada com base na realidade vivida na Babilônia, que se tornou fundamento para diversos acréscimos. Porém, essa teologia se estendeu ao povo no pós-exílio ignorando a realidade de Canaã e daqueles que não foram exilados. A teologia do puro e do impuro poderia ser salvação para os exilados, entretanto, tornou-se morte para a comunidade que não esteve ou que não estava mais no meio dos problemas da Babilônia.

Além disso, é possível afirmar que essa santidade dinâmica trouxe consigo muitas outras implicações para o sistema de vida dos judaítas no pós-exílio. O poder de controle da santidade se tornou a fonte do poder teocrático na província de Yehud do IV século a.C. Entretanto, como explica Foucault (1999), esse meio de poder só funciona se uma classe, neste caso a dominada, permanecer impura e pecadora diante do grupo dominante que são santos e separados.

A afirmativa de Smith (apud DOUGLAS, 1966, p. 26), sobre a rigorosidade, soa de forma perturbadora, quando diz que essa nova edição da legislação imposta ao povo, com muitos acréscimos, constituiu fundamentos de busca por uma pureza que era praticamente impossível de ser alcançada e que gerava muito prejuízo àquela população. Exemplo disso é o acréscimo de impureza em insetos, répteis e lagartos, posta em Levítico 11,20-23 e 2930 , fazendo com que muitos alimentos fossem jogados fora e que vasos, fornos, estufas e utensílios feitos de barro tivessem que ser quebrados. As roupas e demais objetos tocados por esses bichos também tiveram que ser descartados, porém era quase impossível manter o local livre da presença desses insetos. Sobre isso Pagola (2014, p. 237) afirma que o sistema de pureza ritual que se estabeleceu a qualquer custo, sem medir suas consequências internas e externas, resultou no "endurecimento das diferenças e discriminação no seio do próprio judaísmo". Para complementar a tamanha atenção que se dava ao rito de purificação, mesmo após sua execução, ainda era necessário fazer a expiação pela impureza junto ao sacerdote: 
O impuro, depois puro, vai ao templo para expiar sua impureza. Apesar de ter recuperado sua pureza (pois não poderia entrar no santuário de outra forma) ele tem que 'pagar', de forma retroativa, pela impureza precedente. Só o sacerdote garante que a impureza seja totalmente eliminada [...]. Assim funcionava e era introjetada a teocracia judaíta do século quarto antes de Cristo! Os valores populares, as relações sociais preexistentes, a preocupação com os mais pobres que estavam no código da aliança e no código deuteronômico, serão retomadas e até aperfeiçoadas pelo código do Levítico. Mas tudo ficará 'envolvido' pelos critérios de santidade e de pureza. (GALLAZI, 2002, p. 191).

Certamente, a Lei que pesava sobre os ombros dos pobres e oprimidos, não pesava igualmente sobre os ombros dos religiosos. E este cenário era "prato cheio" para o controle social dos puros sobre os impuros. A hierarquia dos puros que vigiavam e sancionavam os impuros se estabeleceu com tamanha força que já não se percebia mais os princípios básicos de justiça, dignidade e misericórdia que revelavam o Deus santo de Israel, que tirou um povo da escravidão do Egito sem que eles nada tivessem a oferecer de volta a Deus. Além disso, Deus não apenas os libertou, como também lhes supriu todas as necessidades. A teologia que apresenta o Deus do puro e do impuro, se torna legitimadora de castigo e sofrimento.

Esta teologia disciplinadora, castigadora e se separatista que acabou se estendendo ao longo dos anos da história de Israel. Quanto mais ela era imposta ao povo, mais poder os sacerdotes e governantes locais tinham sobre os fiéis. A força da nova interpretação da lei, feita sob a experiência exílica, permitiu desenvolver, juntamente, um esquema político de controle que dificilmente seria quebrado. Tanto é que no primeiro século depois de Cristo, as raízes e os fundamentos da fé judaica estavam alicerçados nessa santidade dinâmica, que é perdida e reconquistada todos os dias. Mesmo com as mudanças de governo que a Palestina sofreu na mão de diferentes impérios a cada século, a forma de compreender e viver o código de santidade perdurou e, junto com ele, perdurou no seio do povo uma prática discriminatória, preconceituosa, egoísta, egocêntrica e, em muitos casos, desumana.

A presença marcante dos levitas e sacerdotes tornou a liturgia um rito e um espaço importante para que a identidade dos exilados fosse preservada. A devoção à tradição histórica e a redação das Leis era o que trazia aos deportados união e esperança. Esse agrupamento em torno da liturgia, com exaltação da Lei e da tradição é, aparentemente, o que norteou o povo a partir do exílio, atribuindo normatividade a elementos como sábado, leitura da lei, circuncisão etc. A teologia dos deportados, a saber a do puro e do impuro, trouxe ao povo de Israel uma disciplina religiosa jamais vista nas reformas anteriores.

\section{Centro e periferia: uma geografia do puro e do impuro}

A pureza e a impureza também podem ser pensadas como elementos de organização e de estratificação social. Borg $(1984$, p. 83), em sua obra sobre santidade e política, afirma que a santidade, que ele considera sinônimo de pureza, deveria diferenciar o povo de Israel dos demais povos, entretanto, acabou afetando a sociedade interna, criando grupos de diferentes estratos sociais, com mais ou menos poder, mais ou menos direitos, tudo com base no quão rigoroso era o cumprimento das exigências de pureza. 
O pós-exílio trouxe uma inovação para a estrutura social de Israel, ou seja, as classes foram organizadas não somente segundo as categorias econômicas, rico ou pobre, mas segundo as categorias de pureza e impureza. Nesse sentido, apresenta-se uma análise da divisão que se formou, a partir do conceito de centro e periferia. Rossi (2015), explica este conceito dizendo que "trata-se de um esquema inerentemente especial em sua organização e que dá primazia ao centro em detrimento da periferia"; um esquema que está estruturado em padrões que são capazes "de classificar a distância conceitual e percepção, orientando do mais distante para o mais próximo e do menos importante para o mais importante" (ROSSI, 2015, p. 401).

O conceito de centro-periferia começa a se desenvolver de fato e com mais clareza no meio dos pensadores ligados à economia. É por volta dos anos de 1940 que os termos se popularizam. O centro e a periferia são tidos como uma "relação de exploração e dominação" (PEREIRA, 2015, p. 15), os quais alimenta cada vez mais a desigualdade no mundo. Pereira explica que:

na estrutura de toda sociedade, está presente uma zona central, um núcleo a partir do qual emana todo um conjunto simbólico composto por valores, crenças, ideias e julgamentos éticos e morais que determinam a forma de viver e de pensar não apenas das pessoas que vivem nessas regiões centrais, mas também determinam a existência dos indivíduos das sociedades que compõem a periferia do sistema social (PEREIRA, 2015, p. 115).

Uma região é periférica, portanto, quando seu conjunto de valores não consegue ser influenciado pelos valores que efluem do centro. O centro, por sua vez, na figura de seus líderes, faz serem aceitos os modelos que consideram importantes, sagrados e positivos, de acordo com o planejamento estrutural político econômico que possuem. A cultura, a ideologia e o estilo de vida são determinados por essa região central, que passa a dominar seus correlatos periféricos.

Segundo os estudos de Tebes (2008, p. 10), essa relação está na ideia de que o subdesenvolvimento das periferias é o resultado de sua relação com o centro e vice-versa. Nesse sentido, a posição de um não pode ser entendida sem a posição do outro. Os centros controlam as formas de trabalhos produtivos e organizacionais, são mais desenvolvidos tecnologicamente, bem como possuem uma hegemonia política e ideológica para impor seus interesses. As periferias, por sua vez, "têm formas produtivas e laborais menos complexas, e estão em uma posição de inferioridade política em relação ao centro".

Rodriguez (1981, p. 38) alerta que o desenvolvimento do centro agrava e, até mesmo, perpetua, os problemas que causam o subdesenvolvimento das periferias. Liverani (2017, p. 81) ressalta que uma das características do centro é sua singularidade, a periferia por sua vez é plural, dela é extraída grande parte da matéria prima que o centro necessita. Por isso, aqueles que fazem parte do centro não desejam simplesmente conquistar as periferias e fazê-las aderir a sua cultura e suas regras, mais do que isso, aqueles que estão na posição central, de inclusão, de aceitação, precisam explorar o progresso organizacional e técnico, ou seja, o monopólio do império central.

Essa estrutura pode muito bem ser percebida no cenário sociorreligioso de Israel. Neste caso, porém, o que definia esse grau de superioridade, de desenvolvimento e de influência, era a capacidade das famílias de cumprirem com a lei imposta pelos sacerdotes e com auxílio dos governantes. A condição inclusiva estava na capacidade de se amoldarem aos padrões propostos pelos líderes religiosos, porque, na vivência social de Israel, a crença refletia em todas as outras dimensões, como nas dimensões econômica, 
educacional, assim como nas relacionais entre as pessoas comuns, entre estes e os líderes, entre os nativos e os estrangeiros etc.

Todas essas dimensões relacionais estabeleciam os limites e a capacidade de desenvolvimento do povo de Israel, por isso, aqueles que não pudessem respeitar as mais básicas leis, como o sábado, o afastamento de profissões profanas (pescadores, médicos, carpinteiros), o cumprimento dos rituais de purificação, dos sacrifícios e as ofertas que eram exigidos pelo Templo, eram excluídos, mantidos à parte e explorados. Suas vidas estavam fadadas à periferia.

Sobre esta dinâmica de centro-periferia, Rossi (2015, p. 401) explica que "o centro é concentração do essencial, do aceitável, do apropriado e do sagrado, enquanto o insignificante, ofensivo e impuro é empurrado para periferia". Entretanto, essa divisão não acontece por acaso. Liverani (2005, p. 429), comentando sobre esse processo de autentificar a lei, trabalha os critérios de pureza, as normas de exclusão e de castigo, assim como os demais procedimentos que aparentemente tentavam trazer o povo de volta à normalidade, como um instrumento consciente de controle por parte dos sacerdotes, ou seja, não é por mero acaso que as normas de santidade aumentavam cada vez mais em volume, em detalhes, em severidade, tornando-se impossíveis de alcance por parte dos fracos. Existiam interesses muito claros para a edição dessas leis. Por meio delas se legitimava a exploração dos vulneráveis e o consequente enriquecimento dos exploradores. Dessa forma, crescia um relacionamento opressivo e desigual entre as classes. Pixley (1990, p. 95) entende esse cenário como um conflito entre os autóctones (os que permaneceram na terra durante o exílio) e a golá (os que foram exilados e retornaram posteriormente).

De uma forma resumida, pode-se dizer que essa divisão se dá, respectivamente, entre a classe dos camponeses e latifundiários que, aparentemente, estão enfraquecidos, estão pobres, vítimas da desorganização do período babilônico, precisando enfrentar a oposição que vem de um exílio "bem organizado em torno de um projeto religioso e sacerdotal, com apoio econômico e político das autoridades persas" (PIXLEY, 1990, p. 95). Esse conflito de poder pode ser percebido também na literatura profética da época, como em Ageu e Zacarias, os quais estão ao lado da golá, incentivando a reconstrução do Templo e o cumprimento rigoroso da lei, inclusive a de ofertas, dízimos, sacrifícios e outros.

Em Isaias 58 é possível encontrar um retrato da relação entre as pessoas no Templo. Citando o rito do jejum, tão significativo no calendário litúrgico dos sacerdotes do pósexílio, o profeta diz que o jejum desejado por Javé é a libertação do oprimido, dar comida ao faminto, acabar com a injustiça, ajudar o próximo, vestir aquele que está nu (Is 58). O profeta alerta sobre a injustiça social e a ignorância por parte daqueles que achavam estarem puros, santos, imaculados apenas por cumprirem a Lei. Esse modelo de santificação promove a divisão entre o que é central, inserido no modelo, e o que é periférico, fora do padrão.

\section{Considerações finais}

Assim como as vertentes políticas contemporâneas, que pensam na sociedade a partir do lucro, do retorno, do poder, do status e da acumulação de riquezas, nos quais se vê que a distribuição não igualitária da renda e a exploração da mão de obra dos fracos leva um grande número de pessoas a viveram na periferia, no sistema do puro e do impuro, a relação econômica também tinha grande valia. 
O Templo era um gerador importante de riquezas para o império. A exploração dos impuros era um dos meios de manter o tesouro do Templo sempre abastecido. Além disso, com tantas proibições, era necessário que houvesse alguém para fazer o trabalho comum, o considerado sujo por esta nova ideologia: pescador, carpinteiro, médico, parteira, dentre tantas outras profissões que nem sempre poderiam se adequar aos sábados e nem sempre poderiam restringir o contato com sangue, com o defunto. Profissões que acabavam desrespeitando a lei, mas indispensáveis para sustento e sobrevivência da população. Elas serviam para suprir as necessidades da elite, para manter o conforto e a segurança dos superiores, mas não permitiam que os demais desfrutassem disso. A periferia é o lugar da insegurança, da insatisfação das necessidades básicas, da poluição, da falta de higiene, é o lugar da vida caótica. Como aponta de Rossi (2015) o centro sempre deseja ser o local em que impera a plenitude da glória.

Chegando mais próximo ao contexto social em que Jesus viveu, vê-se ainda a existência das periferias. A Galileia, como retrata Pagola (2014), era uma sociedade agrária. Toda a região estava destinada ao cultivo, todo o seu solo estava sendo aproveitado e toda a população empenhava seu trabalho nisso. Exceto alguns: aqueles que formam as elites da cidade estavam ocupados com o governo, com a administração, com arrecadação de impostos e com a vigilância militar. Segundo Pagola, para os camponeses: "É um trabalho duro, porque só se pode contar com a ajuda de alguns bois, burros e camelos. Os camponeses das aldeias consomem suas forças arando, vindimando ou ceifando as messes com a foice" (PAGOLA, 2014, p. 41).

Nessas periferias não estavam só os camponeses, mas também outros como os pescadores. Até mesmo os mais pobres, que pescavam às margens, tinham seus trabalhos controlados por arrecadadores de impostos de Antipas. Era necessário pagar taxas pelas terras e taxas até para pescar. Com o controle do Império e com a pequena parcela de judeus que tinham posição religiosa importante e que eram aliados ao império, o restante se tornou vítima de uma enorme desigualdade de recursos. Pagola (2014, p. 44) salienta que os camponeses sustentavam a economia do país e produziam "o necessário para manter a minoria dirigente". Com isso, era necessário controlar a produção deles, a fim de sugar-lhes o máximo possível. Os mecanismos de controle são justamente as taxas, os tributos, os impostos e, por fim, a Lei com seus dízimos e demais tributos sagrados exigidos pelo Templo, por intermédio dos sacerdotes.

Este era o contexto de vida de Jesus. Em que uns eram privilegiados, detinham o controle e o poder, enquanto outros eram segregados, explorados e abandonados. Vítimas de um sistema em que os líderes almejavam uma santidade não para estarem separados a serviço de Javé, mas para serem vistos, aplaudidos, saciados em seus desejos individuais e, também, para que suas imagens de seres imaculados escancarassem mais ainda a fraqueza e a necessidade dos outros.

Assim, na dinâmica do centro-periferia, percebe-se o distanciamento entre duas categorias de sujeitos. Mas não se tratava de uma dinâmica inocente, Cardoso (2018) afirma que "a desigualdade social é a maior evidência da existência de corrupção, roubo, suborno, exploração e crime". O centro e a periferia são o retrato perfeito da desigualdade proposital. O distúrbio social que gera o caos e que precisa ser excluído é definido por uma classe. A classe que controla e que detém o poder absoluto sobre o centro. São eles os definidores dos que ficarão na periferia. 
Como cristão de nossos tempos, precisamos repensar e refletir se nossas teologias são pautadas no evangelho de Jesus ou se guardam as raízes da teologia pós-exílica do puro e do impuro, do centro e da periferia, da exclusão e da exploração.

\section{Referências}

BÍBLIA Hebraica Stuttgartensia. 5. ed. Stuttgart: Deutsche Bibelgesellschaft; Barueri: Sociedade Bíblica do Brasil, 1990

BORG, Marcus J. Conflict, holiness, and politics in the teachings of Jesus. New York: E. Mellen, 1984.

CARDOSO, Nancy. Nenhuma riqueza é inocente. Exercícios com redes de corrupção שָ. Revista de Interpretação Bíblica Latino-Americana, São Bernardo do Campo, v. 78, n. 2, p. 5-18, 2018.

DOUGLAS, Mary. Pureza e Perigo. São Paulo: Editora Perspectiva, 1966.

FOUCALT, Michel. Vigiar e punir: nascimento da prisão. Petrópolis, Vozes, 1987.

GALLAZZI, A. A Teocracia Sadocita: sua história e ideologia. Macapá: Biblioteca de Estudos Bíblicos, 2002.

KESSLER, Rainer. História social do antigo Israel. São Paulo: Paulinas, 2009.

KIRK, J. Andrew. O que é missão? Londrina: Descoberta, 2006.

WESTERMANN, Claus. JENNI, Ernst. Theological Lexicon of the Old Testament. North Shore: Hendrickson Pub, 1997.

LIVERANI, Mario. Más allá de la Biblia. Historia Antigua de Israel. Barcelona: Crítica, 2005.

MARIANNO, Lília Dias. Impureza: Sexualidade e saúde pública no Judaísmo do período persa. $R e$ vista Vértices, São Paulo, n. 11, p. 110-130, 2011.

NOVA Bíblia Pastoral. São Paulo: Paulus, 2014.

PAGOLA, José Antonio. Jesus: aproximação histórica. 7. ed. Petrópolis: Vozes, 2014.

PEREIRA, Vinicius Vieira. A produção da relação centro e periferia no pensamento econômico: das teses marxistas do imperialismo capitalista às teorias da dependência. 2015. Tese (Doutorado em Economia) - Universidade Federal de Minas Gerais, Belo Horizonte, 2015.

PIXLEY, Jorge. A história de Israel a partir dos pobres. Petrópolis: Vozes, 1990.

RODRIGUEZ, Octavio. Teoria do subdesenvolvimento da Cepal. Rio de Janeiro: Forense Universitária, 1981.

ROSSI, Luiz Alexandre Solano. Vocação para os pequeninos: do centro para a periferia. Leitura de Isaías 6,1-13. Grande Sinal, Petrópolis, v. 69, n. 4, p. 401-413, 2015.

SCARDELAI, Donizete. O escriba Esdras e o Judaísmo. São Paulo: Paulus Editora 2012. E-book Kindle.

STRONG, James. Dicionário Bíblico Strong. Léxico Hebraico, Aramaico e Grego de Strong. Barueri: Sociedade Bíblica do Brasil, 2002.

TEBES, Juan Manoel. Centro y periferia en el mundo antiguo. El Negev y sus interacciones con Egipto, Asiria, y el Levante en la Edad del Hierro (1200-586 a.C.). 2. ed. Buenos Aires: Society of 
Biblical Literature - Centro de Estudios de Historia del Antiguo Oriente, Universidad Católica Argentina, 2008.

WOLFF, Hans Walter. Antropologia do Antigo Testamento. São Paulo: Hagnos, 2007.

ZABATIERO, Júlio Paulo Tavares. Uma história cultural de Israel. São Paulo: Paulus, 2013. 